\title{
Optimism in Portuguese Adolescents: The Role of Anxiety and Positive Affect*
}

\section{Optimismo en adolescentes portugueses: el papel de la ansiedad y el afecto positivo}

\author{
FÁbio Gonçalves \\ Práctica privada, Portugal \\ ORCID: https://orcid.org/0000-0003-2031-7956 \\ JoAnA Vieira dos SANTOS ${ }^{\mathrm{a}}$ \\ Universidade do Algarve, Portugal \\ ORCID: https://orcid.org/0000-0003-2612-8056 \\ Luís SÉrgio Vieira \\ Universidade do Algarve, Portugal \\ ORCID: https://orcid.org/0000-0001-8143-0923
}

a Correspondence author. Email: jcsantos@ualg.pt

How to cite: Gonçalves, F. Vieira dos Santos, J., \& Vieira, L. S. (2020). Optimism in Portuguese adolescents: The role of anxiety and positive affect. Universitas Psychologica, 19, 1-14. https://doi.org/10.1 1144/Javeriana.upsy19.opar
Received: 09 April 2019 | Accepted: 27 October 2020

\begin{abstract}
The higher prevalence of anxiety and depression disorders in children and adolescents and the persistence of these disorders in adulthood show how important it is to investigate these concepts. Simultaneously, if we better understand the antecedents of, for example, anxiety, it will be more advantageous to define and implement some programs specifically for those ages. Like in adults, some investigations propose to study the effect of anxiety on optimism on samples of children or adolescents. In this study, we analyze the relations between anxiety, optimism, and affect in a sample of 155 students (mean age $=12$ years). We took a particular interest in investigating the direction of influence between anxiety and optimism. The results showed a positive association between positive affect and anxious coping, and predictive power of these variables in explaining optimism, which seems to result from a contribution equivalent to that described on the two-factor structure of affectivity.

Keywords

Optimism; Anxiety; Positive Affects; Adolescents.
\end{abstract}

\section{RESUMEN}

La mayor prevalencia de trastornos de ansiedad y depresión en niños y adolescentes y la persistencia de estos trastornos en la edad adulta muestra la importancia de investigar estos conceptos. Simultáneamente, si entendemos mejor los antecedentes de, por ejemplo, la ansiedad, será más ventajoso definir e implementar algunos programas específicamente para esas edades. Al igual que en los adultos, algunas investigaciones proponen estudiar el efecto de la ansiedad sobre el optimismo, en muestras de niños $\mathrm{o}$ adolescentes. En este estudio analizamos las relaciones entre ansiedad, optimismo y afecto en una muestra de 155 estudiantes (edad media $=12$ años). Nos interesó especialmente investigar la dirección de la influencia entre la ansiedad y el optimismo. Los resultados mostraron una asociación positiva entre el afecto positivo y el afrontamiento ansioso, así como el poder predictivo de estas variables para explicar el optimismo, que parece resultar de una contribución equivalente a la descrita sobre la estructura bifactorial de la afectividad.

Palabras clave

Optimismo; Ansiedad; Afectos positivos; Adolescentes. 
Polanczyk et al. (2015), on a meta-analysis of the worldwide prevalence of mental disorders in children and adolescents, estimated that $13.4 \%$ of children and adolescents (6-18 years of age) have some form of mental disorder. Anxiety disorders showed the highest prevalence rate $(6.5 \%)$. In this way, it is imperative to study the factors that contribute to the initiation, maintenance, or augmentation of anxiety, to fasten the detection of pathological anxiety and develop efficient treatments (Voltas et al., 2017).

A recent work (Diaconu-Gherasim \& Mãirean, 2017) found a positive correlation between dispositional optimism and judgement of future positive life events while also finding that dispositional optimism did not correlate with judgment of future adverse life events. Indeed, these results suggest that optimists have a higher tendency to judge positive life events as more likely to happen to them. Affective states moderated this relation.

Studies that investigate positive and negative affect on samples of children and adolescents are essential, mainly because of the higher prevalence of anxiety and depression disorders on these groups and the fact that these disorders tend to persist in adulthood (Laurent et al., 1999).

Regarding the relation between anxiety and optimism, like previously mentioned, optimists report more positive emotions (Carver \& Scheier, 1998), so it is expected that optimists do not show great levels of anxiety, being that anxiety is a negative emotion. There seems to be an inverse relationship between anxiety and optimism, revealed by systematical negative correlations being found in investigations that study these constructs (e.g., Gustems-Carnicer et al., 2017). In the previously referenced study, pessimism and anxiety were positively correlated.

\section{Literature Review}

\author{
Anxiety
}

Anxiety is a reaction typically displayed in a situation characterized by emotional or physical pressure (Özen, 2017). According to Lang (1968), symptoms of anxiety can be cognitive (e.g., worry thoughts), physiological (e.g., shortness of breath), or behavioral (e.g., avoidance).

Hartmann (2017) distinguishes between normal and pathological anxiety: When someone is in a naturally threatening or scary situation, anxiety is a normal and understandable reaction; On the other hand, when an individual finds himself in a "normal" situation (e.g., riding a bus or leaving their house) and reacts with anxiety, or anticipates harm in an illogical way, one could consider the diagnosis of an anxiety disorder/ pathological anxiety.

Anxiety often relates to other variables. It is known that social anxiety, for example, shows a bilateral relationship with alcohol consumption. That is, individuals with higher social anxiety tend to drink more alcohol as they believe that drinking may facilitate social interaction, while on the other hand, heavy drinking increases the symptoms of anxiety (Chow et al., 2018).

In children and adolescents, anxiety disorders are a prevalent form of psychopathology and usually impair academic performance, socialization, and family functioning (Keeley \& Storch, 2009). On the contrary, "normal" or "healthy" anxiety can be seen in a positive way, as it can help individuals optimizing their performances and overcoming obstacles in their daily life (Rosen, 2008). For example, the previous author concluded that the right "amount" of anxiety helps company leaders to perform at their best level, build better teams and improve productivity and morale. Likewise, in our previous study (Gonçalves et al., 2018), we found a positive correlation between anxious coping and satisfaction with school (students with higher levels of anxious coping had higher levels of satisfaction with 
school), leading us to the hypothesis that nonpathological anxiety must be favorable to student 's academic performance, leading to higher levels of satisfaction with school.

\section{Optimism}

Scheier and Carver (1985) distinguish between optimists and pessimists. According to the authors, optimists believe that good things will happen to them instead of bad ones. Contrarily, pessimists believe that bad things are more likely to happen to them instead of good ones.

Carver et al. (2010), in their review, concluded that being optimistic gives a great advantage to the individual, compared to pessimism, in several domains of his life. Specifically, optimists reported more positive emotions and benefits in subjective well-being (Carver \& Scheier, 1998). In health contexts, the optimists showed better quality of life five years after coronary artery bypass surgery (Scheier et al., 1989). Also, in health contexts, a study from Palgi (2013) found that the number of ongoing cumulative chronic stressors was associated with lower levels of optimism and higher levels of pessimism. Regarding the educational context, the pessimists had approximately twice the dropout from school rate than optimists (e.g., Solberg Nes et al., 2009). The optimists showed a more significant increase in social relations after the first semester of college (Brissette et al., 2002).

However, there are some cases where optimism is not advantageous, especially if there is a belief that positive outcomes will come when objective evidence shows that they will not (unrealistic optimism) (Shepperd et al., 2013). For example, Gibson and Sanbonmatsu (2004) developed three gambling studies whose results propose that the higher tendency to disengage observed in pessimists can be favorable. In the first study optimists were more likely to keep on gambling after losses when comparing optimists to pessimists. The second study showed that optimists did not reduce their betting and positive expectations after losing. In the last study, the authors observed that optimists had more reports of near wins than pessimists did.

Studies on optimism, in their majority, have been using samples of adults. Studies that investigate optimism in children and adolescents (e.g., Bagana et al., 2010) are critical because of the frightening prevalence of anxiety, depression, and suicide rates in these age groups (Gillham \& Reivich, 2004).

\section{Positive and negative affects}

Watson et al. (1988) define positive affect as the level of enthusiasm, activeness, and alertness felt by an individual. On the other hand, the authors define negative affect as the level of subjective distress and aversive moods (e.g., anger, disgust, fear) felt by an individual.

Besides representing a hedonic tone, these dimensions also express the degree of engagement-disengagement with the environment. High levels of positive affect translate into pleasurable engagement with the environment, and high levels of negative affect translate into unpleasant engagement or disengagement with the environment (Lonigan et al., 2003).

Together with life satisfaction, positive and negative affect comprise a broader construct, subjective well-being (Diener, 2000). Subjective well-being is a self-evaluation of an individual's life that includes cognitive measures (life satisfaction) and emotional ones (positive and negative affect) (Diener et al., 2003).

High levels of positive affect are related to confidence, optimism, prosocial behavior, physical well-being, and more effective coping strategies (Lyubomirsky et al., 2005). In contrast, a preponderance of negative affect is associated with more stress and depression, poorer psychological and physical health, and lower self-esteem (Dua, 1993).

The higher prevalence of anxiety and depression disorders in children and adolescents and the persistence of these disorders in adulthood (Laurent et al., 1999) show how important it is to investigate these concepts. 
Simultaneously, if we better understand the antecedents of, for example, anxiety, it will be more advantageous to define and implement some programs specifically for those ages.

\section{Study objectives and hypothesis}

Anxiety can be considered a form of negative affect (Dewberry \& Richardson, 1990), so positive correlations between anxiety and negative affect are expected. On the other hand, anxiety is commonly negatively correlated with positive affect (Kashdan, 2007).

So, based on those studies, we defined the hypothesis:

H1: Anxiety dimensions are negatively correlated to optimism.

H2: Anxiety dimensions are negatively correlated to positive affect.

H3: Anxiety dimensions are positively correlated to negative affect.

We can also mention the relations between optimism/pessimism and positive/negative affect. Diener et al. (1999) found that these concepts correlate in a sense that a person with high dispositional optimism will work harder for their objectives, being more likely to achieve them, thus leading to greater positive affect. However, this effect can also be explained the other way around, that is, individuals that feel more positive emotions will have greater optimism.

Several investigations have found correlations that confirm what was previously stated, presenting positive correlations between optimism/positive affect and pessimism/negative affect and negative correlations between optimism/negative affect and pessimism/positive affect (e.g., Esteve et al., 2018; Ramírez-Maestre et al., 2018).

Based on presented previous studies, we hypothesis:

H4: Optimism is positively correlated to positive affect.

$\mathrm{H}$ 5: Optimism is negatively correlated to negative affect.
The majority of literature places optimism/ pessimism as the "cause" of levels of anxiety. For example, Barber and Starkey (2015) investigated the predictors of anxiety on hospitalized pregnant New Zealand women and a community control sample. Dispositional optimism was a significant predictor of low levels of anxiety in both groups.

Another example, Tang et al. (2016), aimed to verify the effects of perceived risk, knowledge, optimism, pessimism, and social trust on anxiety among a population at risk. Social trust, perceived risk, pessimism, knowledge, and optimism had a significant combined effect on anxiety, explaining $45.3 \%$ of its variance. A combination of social trust, perceived risk, and pessimism explained $42.0 \%$ of the variance in anxiety.

Like in adults, some investigations propose to study the effect of anxiety on optimism on samples of children or adolescents (e.g., Roberts et al., 2018; Rooney et al., 2013). All the previous articles refer to the Aussie Optimism Program-Positive Thinking Skills (AOP-PTS; Rooney et al., 2004), an intervention program design to increase children/adolescent optimism to prevent/diminish anxiety and depression.

Despite the fact that children/adolescents who completed this intervention showed an increase in pro-social behavior and reduced the incidence of suicidal ideation and behavior, for example, there were no decreases in anxiety in any of the previously mentioned studies, contrarily to what was expected.

Nonetheless, some investigators choose to do the opposite, as previously stated, studying the effects of anxiety on optimism. Dewberry and Richardson (1990) investigated the differences in the reported likelihood of occurrence of good/ bad events in samples of anxious (students taking their examinations) and non-anxious (students who had finished their examinations) participants. They concluded that negative affect, especially anxiety, diminished optimism towards positive events.

Dewberry et al. (1990) presented a list of negative events (e.g., being the victim of rape; contracting AIDS; having a drinking problem) and asked their participants to report the level 
of anxiety felt about the possibility of those events happening to them (anxiety) and the probability that those events could happen to them (optimism:less probability representing more optimism). Negative correlations between those two variables lead the authors to conclude that the degree of anxiety felt by a person towards a negative event affects the reported probability that said the event might happen to them (optimism/pessimism).

Both of the previously mentioned studies participants were young adults. In our literature review, no work investigated the effects of anxiety on optimism in children or adolescents. This leads to some questions: what is the best direction to consider between these variables? Do levels of anxiety explain optimism, or is it the other way around? Moreover, what is the role of positive and negative affect in this relationship? We could not find any study that verified both the influence of anxiety on optimism and optimism on anxiety. Also, to the best of our knowledge, the role of positive and negative affect in anxiety and optimism has not been studied yet.

Most works propose a model of explanation based on reviewed literature and only verify one direction of influence or study bilateral relations (two-tailed correlations) (e.g., Bagana et al., 2010; Gustems-Carnicer et al., 2017). Studying the best direction of influence between these constructs is essential for a greater comprehension of how anxiety and optimism work and can help develop more and better interventions/treatments. Interventions/ treatments will be more beneficial if they focus on the "cause" of this relation, leading to the desired positive effects.

In the present study, we analyze anxiety, optimism, and positive/negative affects, with the main objective of studying the relations between these variables. Initially, our interest was in investigating the direction of influence between anxiety and optimism. However, we systematically encountered works that placed affect as a theoretically related variable, both to anxiety and optimism, and so considered it pertinent to study its role in the relation to the previously mentioned variables. As this study is developed with students and the optimism is a protective factor in a turbulent phase of development, and the directions between the variables are not consistent in the literature, we develop the following hypothesis:

H6: Anxiety and affects contributes to the explanation of optimism.

\section{Method}

Sample

We selected a non-random sample of 155 students from different schools in the south of Portugal. The sample was mainly composed of females $(n=86 ; 57 \%)$. Their ages ranged from 9 to 17 years $($ mean $=12.47, \mathrm{SD}=1.46)$. The school years ranged from the $3^{\text {rd }}$ grade to the $9^{\text {th }}$ grade. 122 participants had no double grade, 24 had one previous retention, six had two previous retentions, and three had three previous retentions. Sex is missing for four participants; Age is missing for three participants; School year is missing for one participant.

\section{Data Collection Tools}

Multidimensional Anxiety Scale for Children (MASC, March et al., 1997, Salvador, et al., 2017). The MASC is a 39-item, 4-point, Likert self-report scale (0-Never true about me, 1Rarely true about me, 2-Sometimes true about me, 3-Often true about me) that assesses anxiety in children and adolescents (from eight to 19 years of age). The scale has four major factors/ dimensions (physical symptoms, harm avoidance, social anxiety, and separation/panic). Three of the previous factors can also be divided into two subfactors: physical symptoms (tense/restless and somatic/autonomic), social anxiety (humiliation/ rejection and public performance fears), and harm avoidance (perfectionism and anxious coping).

We used the Portuguese adapted version (Salvador et al., 2017) of the MASC. The 
original study showed good internal reliability, with subfactor's alphas ranging from 0.60 to 0.82 and the four main factors ranging from 0.74 to 0.85. The full scale showed excellent internal reliability, with a Cronbach's alpha of 0.90. In the Portuguese adaptation used for this work (Salvador et al., 2017), subfactor has had alphas that ranged from 0.54 to 0.86 and factors had alphas that ranged from 0.70 to 0.85 . Lastly, in the present study, the subfactor's showed Cronbach's alphas from 0.58 (perfectionism) to 0.87 (humiliation), while the main factors showed alphas between 0.60 (separation) and 0.86 (physical symptoms). The full scale had excellent internal reliability, with a Cronbach's alpha of 0.89 .

Optimism - LOT-R (Life Orientation TestRevised, Scheier et al., 1994; Laranjeira, 2008): The LOT-R is a 10 -item measure optimism versus pessimism. Of the 10 items, three items measure optimism, three items measure pessimism, and four items serve as fillers. Optionally, the three items that measure pessimism can be reverse score to provide a more robust measure of optimism. In the present study, the pessimism dimension showed a poor value of internal reliability $(\alpha=0.59)$, so the pessimism items were reversely scored, as stated. Participants respond on a 5 -point, Likert self-report scale ( 0 -strongly disagree, 1-disagree, 2-neutral, 3-agree, and 4strongly agree).

We used the Portuguese version of the LOT$\mathrm{R}$, adapted and translated for the European Portuguese language by Laranjeira (2008).

In the original study (Scheier et al., 1994), Cronbach's alpha for the entire six items was 0.78, an indicator of a good level of internal consistency. The Portuguese adaptation by Laranjeira (2008) found an alpha of 0.71, an acceptable value. In the present study, Cronbach's alpha for the six items was 0.72, revealing satisfactory internal consistency values.

Positive and Negative Affect Schedule for Children (PANAS-C) (Laurent et al., 1999; da Silva Ameixa, 2013): The PANAS-C is a 27 item, 5-point Likert self-report scale that measures positive and negative affect in children and adolescents. The Portuguese version of the
PANAS-C was used in this work (adapted and validated by da Silva Ameixa (2013). This scale comprises two subscales, positive affect, and negative affect, with 15 items each. Participants are present with a list of emotions in the form of adjectives and are asked to indicate how often they have felt this way over the past two weeks (1-very slightly, 2-a little, 3-moderately, 4-Quite a bit, and 5-Extremely).

In the original study (Laurent et al., 1999), excellent levels of internal consistency were found for the positive affect subscale and the negative affect subscale $(\alpha=0.90 ; \alpha=0.92$, respectively). In the Portuguese adaptation by da Silva Ameixa (2003), the internal consistency values were similarly high $(\alpha=0.85 ; \alpha=0.86$ and $\alpha=0.81$, positive affect, negative affect, and full scale, respectively). Cronbach's alphas were even higher $(\alpha=0.92 ; \alpha=0.94$ and $\alpha=0.89$, for the positive affect, negative affect, and full scale, respectively).

The questionnaire also has some questions to obtain demographic information, including sex, age, school year, and the number doubled in previous school years.

\section{Data collection procedures}

A transversal and quantitative study design accomplished the data collection and analysis for this study. Data was collected using a selffulfillment questionnaire. The teachers of each class guaranteed the application procedures. The data collection was done between June and December of 2017, after the authorization from the Principals of each school from Algarve, South of Portugal.

\section{Data analysis}

Data were analyzed with IBM SPSS 20.0 and AMOS 20.0. The psychometric properties of the questionnaire were studied by a) descriptive statistics, which included computing the averages, standard deviations, skewness and kurtosis whenever appropriate; b) Pearson's correlation coefficients for each scales that 
composed the questionnaire; c) hierarchical multiple regression; d) structural equation modeling using maximum likelihood estimation, considered a robust method when the data does not follow a multivariate normal distribution (Schermelleh-Engel et al., 2003), which did occur in this study.

\section{Results}

This study aimed to establish a theoretical model detailing the relations between the different variables that were analyzed. The proposed model considers the association between the dimensions of anxiety and their explanatory contribution to positive affect and, consequently, their potential explanation to the students' optimism.

\section{Descriptive and Pearson's correlation Statistics}

Our statistical analyses considered only the subfactor's (humiliation fear, public performance fear, perfectionism, anxious coping, tension, and somatic). As there are no subfactor's for the separation anxiety factor, we used the whole scale. The minimum and maximum values, means, and standard deviations for the different variables can be observed in Table 1 .

Table 1.

Descriptive Statistics

\begin{tabular}{lcccccc}
\hline \multicolumn{1}{c}{ Variable } & Minimum & Maximum & Mean & SD & Skewness & Kurtosis \\
\hline Anxiety Humiliation & 0 & 15 & 5.18 & 4.65 & 0.687 & -0.572 \\
Anxiety Public & 0 & 12 & 4.61 & 3.10 & 0.300 & -0.704 \\
Anxiety Perfectionism & 0 & 12 & 7.05 & 2.96 & -0.355 & -0.311 \\
Anxiety Anxious Coping & 0 & 15 & 7.78 & 3.66 & -0.294 & -0.730 \\
Anxiety Tension & 0 & 16 & 4.31 & 4.03 & 1.124 & 0.759 \\
Anxiety Somatic & 0 & 15 & 3.46 & 3.74 & 1.200 & 0.631 \\
Anxiety Sep. Avoidance & 0 & 17 & 6.99 & 4.36 & 0.189 & -0.713 \\
Optimism & 1 & 4 & 2.98 & 0.71 & -0.384 & -0.495 \\
Positive Affect & 22 & 75 & 57.24 & 11.42 & -0.498 & 0.160 \\
Negative Affect & 15 & 75 & 29.04 & 13.01 & 1.677 & 2.742 \\
\hline \multicolumn{7}{c}{ Note. Normality value in } \\
all variables was p < 0.001 & \\
\end{tabular}

Aside from the perfectionism and anxious coping factors, where participants scored above the medium point ( 6 and 7.5 respectively), the participants scored below the medium point in all the other dimensions. On the optimism scale, participants scored slightly above the medium point (2.5). On the positive affect scale, participants scored above the medium point (48.5), while on the negative affect scale, the participants scored below the medium point.

Table 2 also shows the correlations between the different variables in the study. The MASC subfactor's present positive and significant correlations between themselves (from $r=0.232$ to $r=0.622$ ). These dimensions share the same theoretical background, so these values are expected. Although, there are two exceptions: the correlations between anxious coping/tension $(r=0.06, p=0.454)$ and anxious coping/ somatic $(r=0.05, p=0.525)$ are not significant. Optimism correlated weakly, negatively, and significantly with humiliation $(r=-0.17, p=$ $0.039)$ and tension $(r=-0.24, p=0.003)$.

Correlations between the anxiety dimensions and positive affect are weak, negative, and significant (from $r=-0.16$ to $r=-0.29$ ), with the exceptions of perfectionism $(r=-0.15, p=$ $0.066)$ and the anxious coping factors $(\mathrm{r}=0.15$, $\mathrm{p}=0.061)$.

Correlations between the anxiety dimensions and negative affect range from weak to moderate are positive and significant (from $r=0.17$ to $r$ $=0.44)$, with the exceptions of perfectionism $(r$ $=-0, p=0.978)$, anxious coping $(r=0.15, p$ $=0.058)$, and separation anxiety $(r=0.10, p=$ 0.199).

Optimism and positive affect presented a moderate, positive, and significant correlation $(r$ $=0.53, p=0)$. Optimism did not correlate significantly with negative affect $(r=-15, p=$ 0.068).

Table 2

Correlation matrix

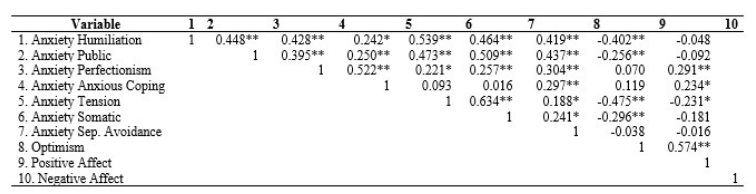

Note. ${ }^{*} p<0.005 * * p<0.001$

Hierarchical multiple regressions

The role of anxiety and positive affects as determinants of optimism was analyzed by 
hierarchical regression. In the first model constructed, we found a significant effect of anxiety dimensions $\left(r^{2}=11 \% ; p=0.015\right)$. When positive and negative affect was added to the model, we found a significant increase in predictive power $\left(\Delta r^{2}=20 \% ; p=0\right)$. Table 3 shows the contribution of each variable to the prediction model.

\section{Table 3}

Hierarchical multiple regression for optimism

\begin{tabular}{llrrr}
\hline Model & \multicolumn{1}{c}{ Variables } & \multicolumn{1}{c}{$\boldsymbol{\beta}$} & \multicolumn{1}{l}{$\boldsymbol{t}$} & \multicolumn{1}{c}{$\boldsymbol{p}$} \\
\hline \multirow{6}{*}{ Humiliation } & -0.115 & -1.130 & 0.260 \\
& Public & -0.112 & -1.131 & 0.260 \\
& Social Anxiety & -0.081 & -0.882 & 0.379 \\
1. & Perfectionism & 0.089 & 0.854 & 0.394 \\
Anxious Coping & $\mathbf{0 . 1 9 7}$ & $\mathbf{1 . 9 9 6}$ & $\mathbf{0 . 0 4 8}$ \\
& Tension & -0.188 & -1.757 & 0.081 \\
Somatic & 0.069 & 0.669 & 0.504 \\
\hline Humiliation & -0.038 & -0.414 & 0.680 \\
Public & -0.056 & -0.631 & 0.529 \\
Social Anxiety & 0.008 & 0.102 & 0.919 \\
Perfectionism & -0.056 & -0.591 & 0.556 \\
Anxious Coping & 0.086 & 0.959 & 0.339 \\
Tension & -0.031 & -0.306 & 0.760 \\
Somatic & 0.074 & 0.796 & 0.427 \\
Positive Affect & $\mathbf{0 . 5 0 9}$ & $\mathbf{6 . 4 5 6}$ & $\mathbf{0}$ \\
Negative Affect & -0.124 & -1.504 & 0.135 \\
\hline
\end{tabular}

Note.Bold remarks significant $p$ values at $p<0.05$.

Our data suggest an effect of the Anxious Coping $(\beta=0.197, p=0.048)$ and Positive Affects $(\beta=0.509 ; p=0)$ on optimism.

\subsection{Confirmatory factor analysis for the model}

We wanted to establish a model to explain the associations between the variables under study, starting both from their theoretical principles and the relations between the different variables. Inferential statistics, namely regression analysis, allowed us to construct a predictive model we assessed using of structural equations (Figure 1). The model's goodness of fit was studied with the aid of different parameters. The ratio between chi-square statistic and the distribution's degrees of freedom $\left(X^{2} / d f=3.588\right)$. The comparative fit index $(\mathrm{CFI})$ and the goodness of fit index (GFI) were, respectively, 0.959 and 0.985 , showing a good model fit (Bentler, 1992; Joreskog, 1996).
Concerning error assessment, the literature suggests that the Standardized Root Mean Square Residual (SRMR) and the Root Mean Square Error of Approximation (RMSEA) should be below 0.05 to verify a good model fit, while values between 0.05 and 0.08 represent a reasonable fit (Browne \& Cudeck, 1993; MacCallum et al., 1996). The SMRM in our model was 0.020, and the RMSEA was 0.030, which may allow us to infer a reasonable model fit.

Figure 1. Confirmatory tested model

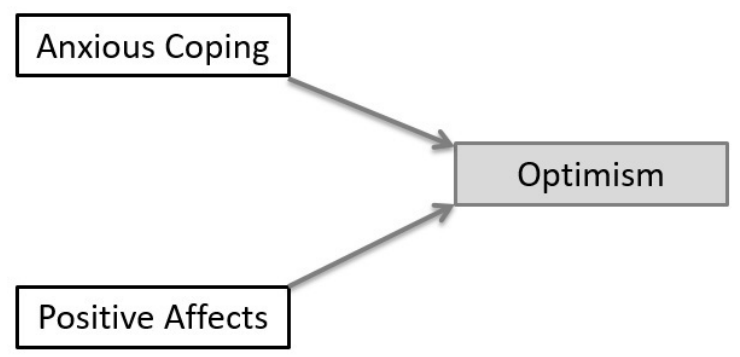

\section{Discussion}

For the present work, we aimed to study the relations between anxiety, optimism, and affect. We took a special interest in investigating the direction of influence between anxiety and optimism. After our initial literature review, we noticed that affect frequently came up in works on anxiety or optimism, so we decided to add positive and negative affect to our investigation, attempting to shed light on the role of affect in the relation between the two previously mentioned variables.

Works like Gillham and Reivich (2004) underline the pronounced prevalence of anxiety, depression, and suicide rates in children and adolescents. Optimism and affect have been linked to anxiety, depression, and others (e.g., Dewberry \& Richardson, 1990).

Thus, investigations that aim to study how these relate and present in children and adolescents are of great importance (Voltas et al., 2017). Also, anxiety and depression disorders tend to persist into adulthood, emphasizing the significance of works investigating these variables 
in samples with younger age (Laurent et al., 1999).

As our main objective was to investigate the relations between variables, five out of our six hypotheses were on correlations between variables or sets of variables.

Firstly, we hypothesized that the anxiety dimensions would correlate negatively with optimism, with the exceptions of anxious coping and perfectionism, which presented positive correlations (non-significant), all the other dimensions correlated negatively with optimism. However, only Humiliation and Tension correlated significantly with optimism. Therefore, we can say that our hypothesis was partially confirmed, as we estimated that all anxiety dimensions would correlate significantly with optimism. This finding replicates results found in other studies, like Gustems-Carnicer et al. (2017), where anxiety correlated negatively with optimism.

Our second and third hypotheses were on the relations between anxiety dimensions and positive and negative affect. We hypothesized that anxiety would correlate negatively with positive affect and positively with negative affect. Besides anxious coping, perfectionism, and separation anxiety, all the other anxiety dimensions correlated negatively and significantly with positive affect, thus partially confirming our hypothesis. This correlation is prevalent in published literature (Kashdan, 2007).

Unexpectedly, anxious coping correlated positively and significantly with positive affect. Although this was a weak correlation, it was a statistically significant one, so we tried to offer a plausible justification for it. In our previous work (Gonçalves et al., 2017), we also found unanticipated positive correlations between anxious coping and other variables (i.e., satisfaction with school). The reviewed literature would only validate negative correlations between anxiety dimensions and other well-being variables due to the "traditional" characterization of anxiety (as a crippling and harmful emotion/reaction) (Keeley \& Storch, 2009). However, some authors have described anxiety as a positive emotion that aids individuals in their daily tasks (e.g., Rosen, 2008). Through that view, we deduce that anxiety dimensions could correlate positively with positive affect and other well-being variables.

Like our former article (Gonçalves et al., 2017), anxious coping and perfectionism showed the most surprising and counterintuitive results. In addition, these variables presented the smallest values of internal consistency (Cronbach alpha), both in the previous study and in the present one. This could also be an explanation for our unpredictable findings regarding anxious coping and perfectionism.

Regarding the correlations between anxiety dimensions and negative affect, positive correlations were expected. Except for anxious coping, perfectionism, and separation anxiety, all the other anxiety dimensions correlated positively and significantly with negative affect. Again, since we did not find a significant positive correlation between these two variables, we can only say that our third hypothesis was partially confirmed. This correlation is equivalent to the one found in Iqbal and Dar (2015), for example, where anxiety correlated positively with negative affect.

We also hypothesized the correlations between optimism and positive/negative affect. Based on some literature (e.g., Esteve et al., 2018; Ramírez-Maestre et al., 2018), we expected positive correlations between optimism and positive affect and negative correlations between optimism and negative affect. Indeed, optimism correlated positively with positive affect and negatively with negative affect, but only the former showed statistical significance. Therefore, despite our fourth hypothesis being confirmed, our data did not support the fifth one due to a lack of statistical significance on the correlation between variables.

The main gap we found in the revised literature was that investigations on the relation between anxiety and optimism often rely on bilateral relations (i.e., two-tailed correlations), which does not offer a saying on cause and effect relations. 
From the starting point, studies on this matter usually have the "cause" and the "effect" well defined, with a robust theoretical background to validate it. For example, Tang et al. (2016) intended to study the effects of optimism (among other variables) on the levels of anxiety among a population at risk. In this example, optimism is clearly the cause, and anxiety the effect. In contrast, we have works like Dewberry and Richardson (1990) investigated the differences in the reported likelihood of good/bad events in samples of anxious and non-anxious participants. In cases like this, anxiety appears as the cause, and optimism as the effect.

Given this discrepancy, we proposed investigating the relations between anxiety, optimism, and affect, a third variable that we decided to include due to its well-verified relation with the former two. Besides that, we supposed that a third variable would contribute to an increase in robustness of our model. Our hypothesis was that anxiety and affects would contribute to the explanation of optimism instead of the opposite which was corroborated.

Resorting to hierarchical multiple regressions, we verified the changes in predictive power when we placed the variables as "cause" or "effect" (i.e., dependent, or independent).

The effect of anxiety on optimism was far greater than the opposite. By adding positive and negative affect to this model, an increase of predictive power was observed. Specifically, anxious coping and positive affect showed a greater effect on optimism. Moreover, this model showed a good fit. Since anxious coping describes the extent to which the person can verify that things are secure, a greater perception seems to contribute to a greater tendency of the individual to manifest generalized expectations of having more positive results in the future than failures. Anxious coping, which is a subcategory of the harm avoidance dimension, indicates that a better evaluation (or even control) of the level of risk inherent in situations (possibly harmful or dangerous) contributes to higher levels of optimism. If control perception is greater, the greater the belief that it will succeed in the future.
The positive association between positive affect and anxious coping and the predictive power of these variables in explaining optimism, seems to result from a contribution equivalent to that described for the two-factor structure of affectivity by Watson and Tellegen (1985). According to their model, higher levels on the engagement axis result from higher values in both positive affect and negative affect. Thus, by analogy, a greater perception of control of the unforeseen or of the dangers seems to contribute to better confidence in obtaining future successes.

In conclusion, at least for our sample, we found that despite bilateral relations between variables, anxiety fits better as a predictor for optimism. This could implicate that changes in levels of anxiety would signify alterations in optimism. Due to the crippling nature of pathological anxiety, this form of negative affect is probably hindering the life of many children and adolescents, making them less optimistic individuals. Anxiety symptoms can be worrying thoughts or even avoidance of a situation, for example. This makes it unlikely for an anxious person to experience life to its fullest, probably resulting in more negative life situations or at least a worst subjective evaluation of said situations (pessimism).

On the other hand, we could propose that treatments or programs designed to control/ diminish anxiety levels would augment the likelihood of positive life events, or at least the subject evaluation of the individual as a positive event. Regulating worrisome, anxious thoughts, managing physically debilitating symptoms, and training the approach on fearful situations look like ideal pathways to reduce anxiety levels and will likely contribute to the emergence of positive life events and positive subjective evaluations about them.

Teaching our children about anxiety and how to control it seems essential for obtaining a healthier and happier future generation of parents, workers, and human beings. 


\section{References}

Bagana, E., Raciu, A., \& Lupu, L. (2011). Self-esteem, optimism and exams' anxiety among high school students. Procedia - Social and Behavioral Sciences, 30, 1331-1338. https://doi.org/10.1016/j.sbspro .2011 .10 .258

Barber, C. C., \& Starkey, N. J. (2015). Predictors of anxiety among pregnant New Zealand women hospitalized for complications and a community comparison group. Midwifery, 31 (9), 888-896. https://doi.org/10.1016/j.m idw.2015.04.017

Bentler, P. M. (1992). On the fit of models to covariances and methodology to the Bulletin. Psychological Bulletin, 112, 400-404. https://doi.org/10.1037/0033-290 9.112.3.400

Brissette, I., Scheier, M. F., \& Carver, C. S. (2002). The role of optimism in social network development, coping, and psychological adjustment during a life transition. Journal of Personality and Social Psychology, 82(1), 102-111. https://doi.org/ 10.1037/0022-3514.82.1.102

Browne, M. W., \& Cudeck, R. (1993). Alternative ways of assessing model fit. In K. Bollen \& J. Long (Ed.). Testing structural equation models (pp. 445-455). Sage.

Carver, C. S., \& Scheier, M. F. (1998). On the selfregulation of behavior. Cambridge University Press. https://doi.org/10.1017/cbo9781139 174794

Carver, C. S., Scheier, M. F., \& Segerstrom, S. C. (2010). Optimism. Clinical Psychology Review, 30(7), 879-889. https://doi.org/10.1 016/j.cpr.2010.01.006

Chow, P. I., Portnow, S., Zhang, D., Salemink, E., Wiers, R. W., \& Teachman, B. A. (2018). Comorbid interpretation and expectancy bias in social anxiety and alcohol use. Anxiety, Stress, Eु Coping, 31(6), 669-685. https://doi.org/10.1080/10 615806.2018 .1521958

Dewberry, C., \& Richardson, S. (1990). Effect of anxiety on optimism. The Journal of Social
Psychology, 130(6), 731-738. https://doi.org /10.1080/00224545.1990.9924625

Dewberry, C., Ing, M., James, S., Nixon, M., \& Richardson, S. (1990). Anxiety and unrealistic optimism. The Journal of Social Psychology, 130(2), 151-156. https://doi.org /10.1080/00224545.1990.9924565

Diaconu-Gherasim, L. R., \& Mãirean, C. (2017). Dispositional optimism, affective states and judgements of future life events. Studia Psychologica, 59(3), 193-205. https://doi.org /10.21909/sp.2017.03.740

Diener, E. (2000). Subjective well-being: The science of happiness and a proposal for a national index. American Psychologist, 55(1), 34-43. https://doi.org/10.1037/0003066x.55.1.34

Diener, E., Oishi, S., \& Lucas, R. E. (2003). Personality, culture, and subjective wellbeing: Emotional and cognitive evaluations of life. Annual Review of Psychology, 54(1), 403-425. https://doi.org/10.1146/annurev. psych.54.101601.145056

Diener, E., Suh, E. M., Lucas, R. E., \& Smith, H. L. (1999). Subjective well-being: Three decades of progress. Psychological Bulletin, 125(2), 276-302. https://doi.org/10.1037/0 033-2909.125.2.276

Dua, J. K. (1993). The role of negative affect and positive affect in stress, depression, selfesteem, assertiveness, Type A behaviors, psychological health, and physical health. Genetic, Social, and General Psychology Monographs, 119(4), 515-552. https://pubm ed.ncbi.nlm.nih.gov/8150272/

Esteve, R., López-Martínez, A. E., Peters, M. L., Serrano-Ibáñez, E. R., RuizPárraga, G. T., \& Ramírez-Maestre, C. (2018). Optimism, Positive and Negative Affect, and Goal Adjustment Strategies: Their Relationship to Activity Patterns in Patients with Chronic Musculoskeletal Pain. Pain Research and Management,2018, 1-12. https://doi.org/10.1155/2018/629171 9

Gibson, B., \& Sanbonmatsu, D. M. (2004). Optimism, Pessimism, and Gambling: The Downside of Optimism. Personality and 
Fábio Gonçalves, Joana Vieira dos Santos, Luís Sérgio Vieira.

Social Psychology Bulletin, 30(2), 149-160. h ttps://doi.org/10.1177/0146167203259929

Gillham, J., \& Reivich, K. (2004). Cultivating Optimism in Childhood and Adolescence. The ANNALS of the American Academy of Political and Social Science, 591(1), 146-163. https://doi.org/10.1177/00027162 03260095

Gonçalves, F., Mendes, A., \& Santos, J. (2017). Ansiedade e satisfação com a vida. Estudo das relações numa amostra de estudantes portugueses. OMNIA Revista Interdisciplinar De Ciências E Artes, 7, 23-40. https://doi.or g/10.23882/OM07-2017-10-03

Gustems-Carnicer, J., Calderón, C., \& Santacana, M. F. (2017). Psychometric properties of the Life Orientation Test (LOT-R) and its relationship with psychological well-being and academic progress in college students. Revista Latinoamericana De Psicología, 49(1), 19-27. https://doi.org/10.1016/j.rlp.2016.05.001

Hartmann, P. M. (2017). Anxiety. Magill's Medical Guide (Online Edition). Salem Press.

Iqbal, N., \& Dar, K. A. (2015). Negative affectivity, depression, and anxiety: Does rumination mediate the links? Journal of Affective Disorders, 181, 18-23. https://doi.o $\mathrm{rg} / 10.1016 /$ j.jad.2015.04.002

Joreskog, K. G. (1996). Testing a simple structure hypothesis in factor analysis. Psychometrika, 31, 165-178. http://dx.doi.org/10.1007/BF0 2289505

Kashdan, T. B. (2007). Social anxiety spectrum and diminished positive experiences: Theoretical synthesis and meta-analysis. Clinical Psychology Review, 27(3), 348-365. https://doi.org/10.1016/j.cpr.2006.12.003

Keeley, M. L., \& Storch, E. A. (2009). Anxiety Disorders in Youth. Journal of Pediatric Nursing, 24(1), 26-40. https://doi.org/10.10 16/j.pedn.2007.08.021

Lang, P. J. (1968). Fear reduction and fear behavior: Problems in treating a construct. In J. M. Shlien (Ed.), Research in Psychotherapy (pp. 90-102). American Psychological Association. https://doi.org/1 0.1037/10546-004
Laranjeira, C. (2008). Tradução e validação portuguesa do revised life orientation test (LOT-R). Universitas Psychologica, 7(2) 469-476. https://revistas.javeriana.edu.co/i ndex.php/revPsycho/article/view/469

Laurent, J., Catanzaro, S. J., Joiner, T. E., Rudolph, K. D., Potter, K. I., Lambert, S., Osborne, L., Gathright, T. (1999). A measure of positive and negative affect for children: Scale development and preliminary validation. Psychological Assessment, 11(3), 326-338. https://doi.org/ 10.1037/1040-3590.11.3.326

Lonigan, C. J., Phillips, B. M., \& Hooe, E. S. (2003). Relations of positive and negative affectivity to anxiety and depression in children: Evidence from a latent variable longitudinal study. Journal of Consulting and Clinical Psychology, 71(3), 465-481. https:// doi.org/10.1037/0022-006x.71.3.465

Lyubomirsky, S., King, L., \& Diener, E. (2005). The benefits of frequent positive affect: Does happiness lead to success? Psychological Bulletin, 131 (6), 803-855. http s://doi.org/10.1037/0033-2909.131.6.803

Maccallum, R. C., Browne, M. W., \& Sugawara, H. M. (1996). Power analysis and determination of size sample for covariance structure modeling. Psychology Methods, 1(2), 130-149. https://doi.org/10.1037/108 2-989X.1.2.130

March, J. S., Parker, J. D., Sullivan, K., Stallings, P., \& Conners, C. K. (1997). The Multidimensional Anxiety Scale for Children (MASC): Factor structure, reliability, and validity. Journal of the American Academy of Child $\mathcal{E}$ Adolescent Psychiatry, 36(4), 554-565. https://doi.org/1 0.1097/00004583-199704000-00019

Özen, G. (2017). The effect of recreational activities on trait and state anxiety levels. Ovidius University Annals, Physical Education and Sport/Science, Movement and Health Series, 18(1), 60-65. https://doi.org/ 10.5281/zenodo. 1133568

Palgi, Y. (2013). Are ongoing cumulative chronic stressors associated with optimism and pessimism in the second half of life? Anxiety, 
Stress EO Coping, 26(6), 674-689. https://doi .org/10.1080/10615806.2013.784901

Polanczyk, G. V., Salum, G. A., Sugaya, L. S., Caye, A., \& Rohde, L. A. (2015). Annual research review: A meta-analysis of the worldwide prevalence of mental disorders in children and adolescents. Journal of Child Psychology and Psychiatry and Allied Disciplines, 56(3), 345-365. https://doi.org/ 10.1111/jcpp. 12381

Ramírez-Maestre, C., Esteve, R., LópezMartínez, A. E., Serrano-Ibáñez, E. R., Ruiz-Párraga, G. T., \& Peters, M. (2018). Goal adjustment and well-being: The role of optimism in patients with chronic pain. Annals of Behavioral Medicine, 53(7), 597-607 https://doi.org/10.1093/abm/kay0 70

Roberts, C. M., Kane, R. T., Rooney, R. M., Pintabona, Y., Baughman, N., Hassan, S., Cross, D., Zubrick, S. R., \& Silburn, S. R. (2018). Efficacy of the Aussie optimism program: Promoting pro-social behavior and preventing suicidality in primary school students. A Randomised-Controlled Trial. Frontiers in Psychology, 8, 1-13. https://doi.o rg/10.3389/fpsyg.2017.01392

Rooney, R., Rudge L., Snowball L., Roberts C., \& Pike L. (2004). The positive thinking program: Prevention manual. Curtin University of Technology.

Rooney, R. M., Morrison, D., Hassan, S., Kane, R., Roberts, C., \& Mancini, V. (2013). Prevention of internalizing disorders in 9-10 year old children: Efficacy of the Aussie Optimism Positive Thinking Skills Program at 30-month follow-up. Frontiers in Psychology, 4, 1-10. https://doi.org/10.3389/ fpsyg.2013.00988

Rosen, R. H. (2008). Embracing uncertainty and anxiety. Leader to Leader, 2008(50), 34-38. https://doi.org/10.1002/ltl.304

Salvador, M. D., Matos, A. P., Oliveira, S., March, J. S., Arnarson, E. Ö, Carey, S. C., \& Craighead, W. E. (2017). A Escala Multidimensional de Ansiedade para Crianças (MASC): Propriedades psicométricas e análise fatorial confirmatória numa amostra de adolescentes portugueses. Revista Iberoamericana De Diagnóstico Y Evaluación - e Avaliação Psicológica, 45(3), 33-46. https ://doi.org/10.21865/ridep45.3.03

Scheier, M. F., \& Carver, C. S. (1985). Optimism, coping, and health: Assessment and implications of generalized outcome expectancies. Health Psychology, 4(3), 219-247. https://doi.org/10.1037//0278-61 33.4.3.219

Scheier, M. F., Carver, C. S., \& Bridges, M. W. (1994). Distinguishing optimism from neuroticism (and trait anxiety, self-mastery, and self-esteem): A reevaluation of the Life Orientation Test. Journal of Personality and Social Psychology, 67(6), 1063-1078. https:/ /doi.org/10.1037//0022-3514.67.6.1063

Scheier, M. F., Matthews, K. A., Owens, J. F., Magovern, G. J., Lefebvre, R. C., Abbott, R. A., \& Carver, C. S. (1989). Dispositional optimism and recovery from coronary artery bypass surgery: The beneficial effects on physical and psychological well-being. Journal of Personality and Social Psychology, 57(6), 1024-1040. https://doi.org/10.1037/ 0022-3514.57.6.1024

Schermelleh-Engel, K., Moosbrugger, H., \& Müller, H. (2003). Evaluating the fit of structural equation models: Tests of significance and descriptive goodness-of-fit measures. Methods of psychological research online, 8(2), 23-74. https://www.researchga te.net/publication/251060246_Evaluating_ the_Fit_of_Structural_Equation_Models Tests_of_Significance_and_Descriptive_G oodness-of-Fit_Measures

Shepperd, J. A., Klein, W. M., Waters, E. A., \& Weinstein, N. D. (2013). Taking Stock of Unrealistic Optimism. Perspectives on Psychological Science, 8(4), 395-411. https:// doi.org/10.1177/1745691613485247

da Silva Ameixa, G. M. (2013). Estudo de adaptação e validação de duas escalas de avaliação da dimensão emocional [Doctoral dissertation, Universidade do Algarve]. Core. https://core.ac.uk/download/pdf/615 23362.pdf 
Solberg Nes, L. S., Evans, D. R., \& Segerstrom, S. C. (2009). Optimism and College Retention: Mediation by Motivation, Performance, and Adjustment. Journal of Applied Social Psychology, 39(8), 1887-1912. https://doi.org/10.1111/j.15591816.2009.00508.x

Tang, Z., Guo, Z., Zhou, L., Xue, S., Zhu, Q., \& Zhu, H. (2016). Combined and Relative Effect Levels of Perceived Risk, Knowledge, Optimism, Pessimism, and Social Trust on Anxiety among Inhabitants Concerning Living on Heavy Metal Contaminated Soil. International Journal of Environmental Research and Public Health, 13(11), 1076, 1-17. https://doi.org/10.3390/ijerph131110 76

Voltas, N., Hernández-Martínez, C., Arija, V., \& Canals, J. (2017). The natural course of anxiety symptoms in early adolescence: Factors related to persistence. Anxiety, Stress, $\mathcal{E}$ Coping, 30 (6), 671-686. https://do i.org/10.1080/10615806.2017.1347642

Watson, D., \& Tellegen, A. (1985). Toward a consensual structure of mood. Psychological Bulletin, 98(2), 219-235. https://doi.org/10. 1037/0033-2909.98.2.219

Watson, D., Clark, L. A., \& Tellegen, A. (1988). Development and validation of brief measures of positive and negative affect: The PANAS scales. Journal of Personality and Social Psychology, 54(6), 1063-1070. https://doi.org/10.1037/0022-3 514.54.6.1063

\section{Notes}

* Research article. This work was funded by national funds through FCT - Fundação para a Ciência e a Tecnologia - as part the project CIP - Ref ${ }^{a}$ UID/PSI/04345/2020 